\title{
Development of Some Electrical Properties of Composites Polymer Based on Nano Copper Particles
}

\author{
T.T. Issa ${ }^{a, *}$, A.A. Mohammed ${ }^{a}$, Z.E. AbaAs ${ }^{b}$ AND F.S. ShOKR ${ }^{c}$ \\ ${ }^{a}$ Department of Physics, College of Science, University of Baghdad, Baghdad, Iraq \\ ${ }^{b}$ State Commission for Research and Development, Ministry of Industry, Baghdad, Iraq \\ ${ }^{c}$ Department of Physics, Faculty of Science and Art, University of King Abdul Aziz, Rabigh, KSA \\ Composites of polyaniline-polyethylene-copper were prepared using different weight percentage of nano copper \\ particles of $100 \mathrm{~nm}$ size. X-ray diffraction and Fourier transform infrared spectroscopy were done to identify the \\ crystal structure of prepared polyaniline and polyaniline-polyethylene- $\mathrm{Cu}$, respectively. Electrical properties for \\ all the combinations of 5,10,15,20, and $25 \mathrm{wt} \%$ copper were examined as electrical conductivity, capacitance, \\ and dielectrical constant. The remarkable improvement in all the electrical properties were indicated after adding \\ nano copper particles, accept the combination P-Ani- $5 \mathrm{wt} \% \mathrm{Cu}$. Scanning electron microscopy results confirm the \\ dispersion of nano copper particles through their microstructure.
}

DOI: 10.12693/APhysPolA.134.457

PACS/topics: composites polymer, nanoparticles, electrical properties

\section{Introduction}

Research in the field of conducting polymer have attracted considerable attraction in the past three decades. Conducting polymer matrices provide an interesting and useful focus for expansion of the fields of polymeric reagent research and molecular engineering. The electrical characteristics of a polymer can be substantially modified when the polymer is mixed with conductive filler such as metal powder, like copper or an intrinsically conducting polymer powder. These conductive polymers composite materials retain some of the advantages of conventional polymers, such as density, cost, and prose's ability. Therefore they present tremendous potential as an alternative to metals in specific applications and widen the range of applications of conductive polymer composite materials. The distribution of the conductive filler phase in a polymer matrix leads to the formation or a conductive network at a rather low critical content filler. Copper powder has been used to obtain conductive polyethylene polyaniline with specific electrical properties. The most important form of polyaniline, green protonated emeraldine is produced by the oxidation polymerization of aniline in aqueous acids e.g. $\mathrm{HCl}$ - the aqueous solutions of aniline hydrochloride mixed with ammonium persulphate. The electrical properties gains leads to a potential application in light emitting diodes, solar cells, sensors, batteries and super capacitors $[1,2]$.

\section{Materials and equipments}

Polyethylene low density ( $\mathrm{CDH}$, India), copper powder (BDH, UK), aniline $\mathrm{C}_{6} \mathrm{H}_{5} \mathrm{NH}_{2}$ (Thomas Bakr, In-

\footnotetext{
*corresponding author; e-mail: alazbrh@yahoo.com
}

dia), $\mathrm{HCl}$, ammonium per sulfate $\left(\mathrm{NH}_{4}\right)_{2} \mathrm{~S}_{2} \mathrm{O}_{8}$ of $99.99 \%$ purity were used in the present work. Doped polyaniline (polyaniline- $\mathrm{HCl}$ ) was chemically synthesized using aniline and ammonium per sulfate as oxidant in 4:1 monomer / oxidant molar ration. $20 \mathrm{ml}$ of aniline was dissolved in $40 \mathrm{ml}$ of $1 \mathrm{~mol} / \mathrm{l}$ aqueous of hydrochloric acid in a $250 \mathrm{ml}$ flask. The dissolution was kept inside a vessel containing mixture of ice and salt at a temperature of about $5{ }^{\circ} \mathrm{C}$. Separately $12 \mathrm{~g}$ of $\left(\mathrm{NH}_{4}\right)_{2} \mathrm{~S}_{2} \mathrm{O}_{8}$ was dissolved in $160 \mathrm{ml}$ of $1 \mathrm{~mol} / \mathrm{l} \mathrm{HCl}$ acid aqueous solution. The acid of $\left(\mathrm{NH}_{4}\right)_{2} \mathrm{~S}_{2} \mathrm{O}_{8}$ was slowly and carefully added into the flask containing aniline acid solution under constant stirring within one hour the reaction was kept at $-5{ }^{\circ} \mathrm{C}$. Its color changed from brown to blue and then green, a solid deposit was formed at the bottom of the reaction flask. The green sediment was filtered, rinsed with $1 \mathrm{~mol} / \mathrm{l} \mathrm{HCl}$ and dried at room temperature for $72 \mathrm{~h}$, the polymer obtained is called emeraldine [3]. Polyethylene of $95 \%$ weight percent was mixed with 5 weight percent polyaniline (emeraldine) as the polymer matrix (P-Ani). Copper powder of 100 nano grain size of weight percent ranging from 5, 10, 15, 20, and 25 were dry mixed for $18 \mathrm{~h}$ with the polymer matrix (P-Ani), each combination of three samples were hot pressed using ESCOPRESS 100 METKON Co., Turkey. The fabricated samples were of disc shape and $1.2 \mathrm{~cm}$ in diameter and $0.8 \mathrm{~cm}$ in thickness. X-ray diffraction was carried out to identify the polyaniline formation and the composites polymer using SHIMADZU XRD-6000, Japan, the 2 theta deg, scanned in the range $10-60^{\circ}$, while the FTIR test was carried out by BROKER, Germany. The DC electrical properties were represented by conductivity tested for all the composites polymer under room temperature, electrical conductivity measured by impedance analyzer 429A, Germany, device under the ASTM standard D150. Scanning electron microscopy were done by using the Zeiss, Germany, instruments. 


\section{Results and discussion}

The prepared polyaniline crystal structure was detected. The X-ray patterns of pure polyaniline are shown in Fig. 1. The main peaks were observed at 2 theta deg $(20.227,25.00)$ as emeraldine salt [4], according to the the ASTM file name 1459 pkk. The characteristic peaks of the combinations P-Ani-10 wt\% Cu and P-Ani $25 \mathrm{wt} \%$ $\mathrm{Cu}$, respectively shown in Fig. 1 . Peaks at 2 theta deg $20.227,25.00$ belong to the polyaniline and the peak 36.50 belongs to the polyethylene while the peak 44.95 belongs to the added copper, according to the ASTM, files name $1460 \mathrm{pkk}$ and $1461 \mathrm{pkk}$. The copper peaks intensity was increased as added copper increases, as shown in the pattern of the combination P-Ani $25 \mathrm{wt} \% \mathrm{Cu}$. The FTIR analysis also reflects the formation of prepared polyaniline as shown in Fig. 2.

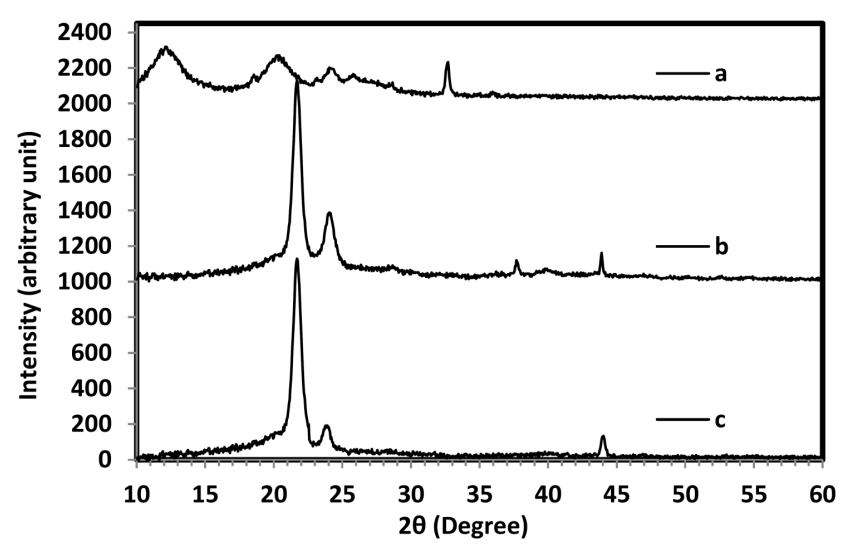

Fig. 1. The X-ray diffraction pattern of $a-$ pure polyaniline (emeraldine), $b-\mathrm{P}$-Ani $10 \mathrm{wt} \% \mathrm{Cu}, c-$ P-Ani 25 wt\% Cu.

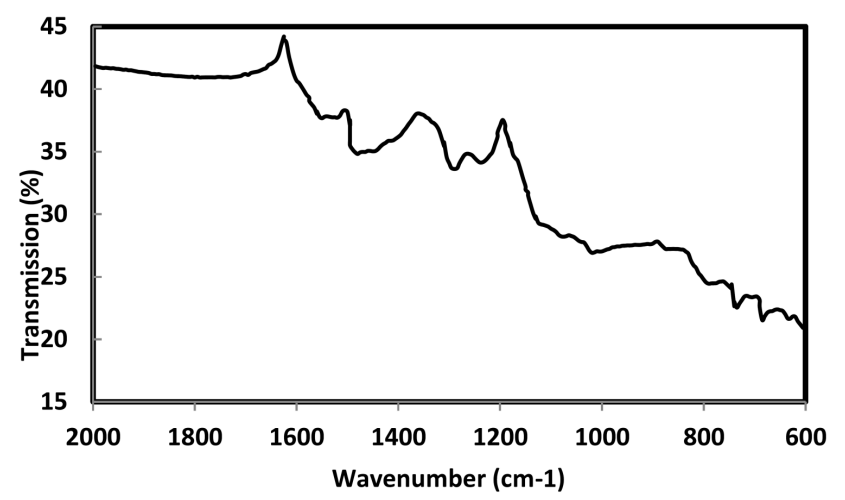

Fig. 2. FTIR spectra of pure polyaniline.

The results got from the electrical test for all fabricated combinations can be shown in Fig. 3. The resulting data shows the decrease at the combination P-Ani $5 \mathrm{wt} \% \mathrm{Cu}$, while the increase was observed at the combinations P-Ani $(10,15,20,25) \mathrm{wt} \% \mathrm{Cu}$. This is because of the copper particles dispersion effect. The homogeneously dispersed in copper particles within the polymer matrix [5] lead to the increase in electrical conductivity and capacitance $[6-8]$, reaching the maximum value at the combination P-Ani $25 \mathrm{wt} \% \mathrm{Cu}$ as shown in Fig. 3 and Fig. 4. The dielectric constant measured under different frequencies gives results reflecting the matching with other electrical properties as shown in Fig. 5. The scanning electron microscopy (SEM) for all combinations was tested as shown in Fig. 6, the well dispersion of copper nano particles can be seen clearly through the combinations P-Ani $(10,15,20,25) \mathrm{wt} \% \mathrm{Cu}$, which indicate the microstructure feature after adding the copper particles.

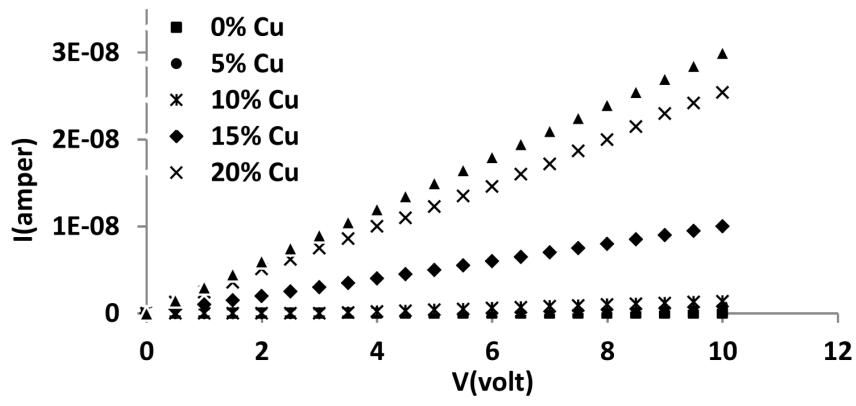

Fig. 3. The electrical test as a function of P-Ani wt\% $\mathrm{Cu}$ composites polymer.

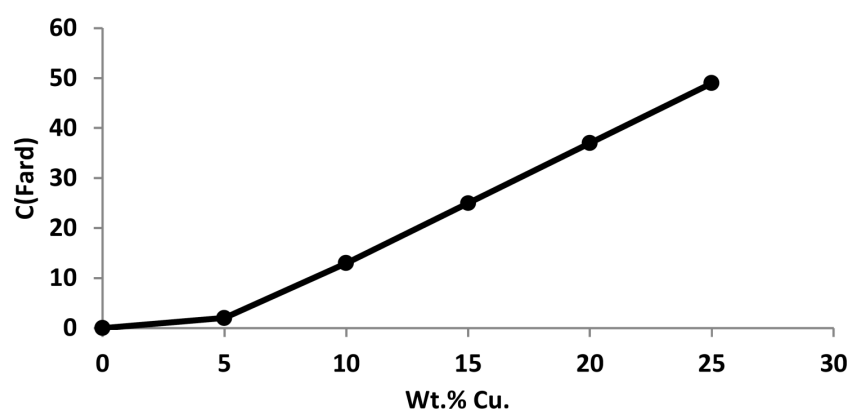

Fig. 4. The capacitance as a function of P-Ani wt\% $\mathrm{Cu}$ composites polymer.

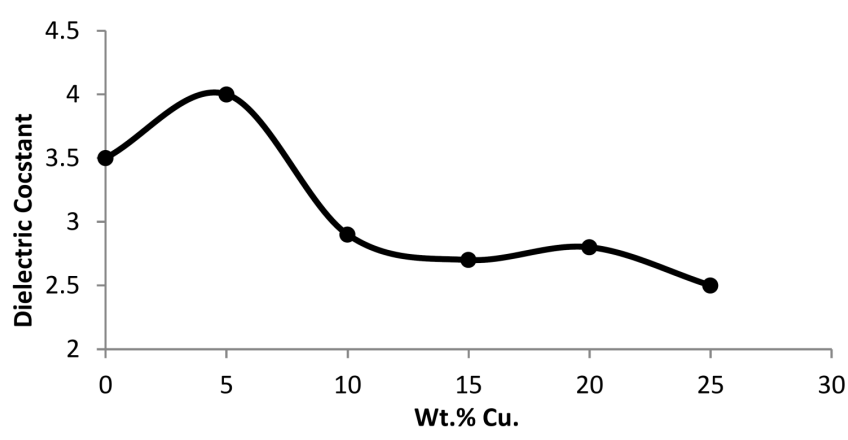

Fig. 5. The dielectric constant as a function of PAni wt $\% \mathrm{Cu}$ composites polymer. 

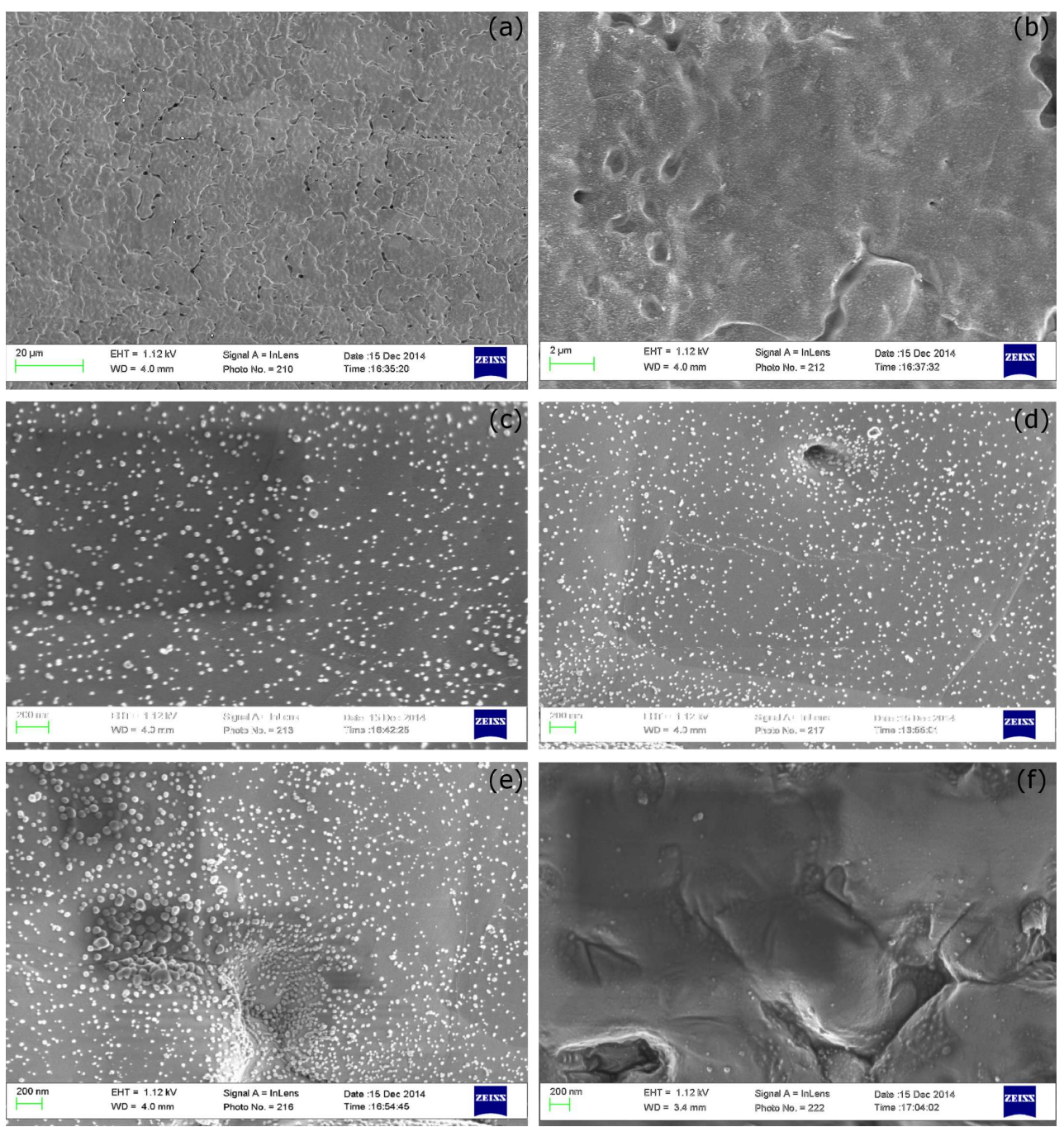

Fig. 6. The SEM images of (a) P-aniline (matrix), (b) P-Ani 5 wt $\% \mathrm{Cu}$, (c) P-Ani 10 wt\% Cu, (d) P-Ani 15 wt $\% \mathrm{Cu}$, (e) P-Ani 20 wt\% Cu, (f) P-Ani 25 wt\% Cu.

\section{Conclusion}

The nano copper added to the polymer matrix leads to remarkable and enhancing the electrical properties in the final composite of polyethylene-polyaniline. Only the combination of $5 \mathrm{wt} \% \mathrm{Cu}$ shows decrease because of the bad homogenization between the dispersed copper particles and the polymer matrix. Scanning electron microscopy shows the evidence of affecting the dispersed nano copper particles for both cases in decrease and increase, respectively.

\section{Acknowledgments}

This work has been supported and offered all the requirements by the State Commission of Research and Development, Ministry of Industry, Iraq.

\section{References}

[1] K. Depa, A. Strachota, J. Stejskal, P. Bober, V. Cimrová, J. Prokeš, M. Trchová, M. Šlouf, J. Hodan, J. Appl. Polym. Sci. 132, 42429 (2015).
[2] J. Honey, M.T. Rinku, J. Joe, K.T. Mathew, J. Rani, Polym. Compos. 28, 588 (2007).

[3] H. Goto, H. Yoneyama, F. Togashi, R. Ohta, A. Tsujimoto, E. Kita, K. Ohshima, J. Chem. Educ. 85 , 1067 (2008).

[4] D.E. Tallman, Y. Pae, G.P. Bierwagen, Corrosion 56, 401 (2000).

[5] A.R. Jabour, Int. J. Hydrogen En. 43, 530 (2018).

[6] Haitao Zheng, Ntombizodwa M. Ncube, Kumar Raju, Nonhlanhla Mphahlele, Mkhulu Mathe, Springer Plus 5, 630 (2016).

[7] Santanu Singha, M. Joy Thomas, in: Proc. 2006 IEEE Conf. on Electrical Insulation and Dielectric Phenomena, USA, 2007.

[8] Safenaz M. Reda1, Sheikha M. Al-Ghannam, Adv. Mater. Phys. Chem. 2, 75 (2012). 